\title{
Development of Low Gly m Bd 30K (P34) Allergen Breeding Lines Using Molecular Marker in Soybean [Glycine max (L.) Merr.]
}

\author{
Kwang-Ho Jeong ${ }^{1 \dagger}$, Man-Soo Choi ${ }^{1 \dagger}$, Seuk-Ki Lee ${ }^{2}$, Min-Jung Seo ${ }^{1}$, Tae-Young Hwang ${ }^{3}$, Hong-Tai Yun ${ }^{1}$, \\ Hong-Sig Kim ${ }^{4}$, Jung-Tae Kim', Young-Up Kwon', Yul-Ho Kim* \\ ${ }^{1}$ National Institute of Crop Science, Rural Development Administration, Suwon 441-857, Korea \\ ${ }^{2}$ Technology Cooperation Bureau, RDA, Suwon 441-707, Korea \\ ${ }^{3}$ National Institute of Animal Science, RDA, Cheonan 331-801, Korea \\ ${ }^{4}$ College of Agriculture, Life \& Environment Sciences, Chungbuk National University, Cheongju, Chungcheongbukdo 361-763, Korea
}

\begin{abstract}
An increasing production of soybean (Glycine max [L.] Merr.)-based food products may limit dietary choices for soy-allergic individuals. Gly $\mathrm{m} \mathrm{Bd} 30 \mathrm{~K}$ (P34) is the main seed allergen causing implications in soybean-sensitive patients. The objective of this research was to develop low allergenic soybean lines with molecular marker. The soybean genome assembly specifies that three copy genes of P34 exist in soybean genome. These are Glyma08g12270, which is expressed at significantly higher level over the other two, Glyma08g12280 and Glyma05g29130. Glyma08g12270 was found inactive and was not expressed in low P34 germplasm accessions. Using a co-dominant marker and a polyclonal antibody, polymorphisms and the quantity of protein produced by Glyma08g12270 were analyzed in the $\mathrm{F}_{2}$ and $\mathrm{F}_{3}$ generations obtained by crossing PI567476 and the Korean cultivar Hwanggum. The molecular marker and polyclonal antibody developed in this study could therefore be effectively used for selecting lines that express P34 at low levels. Selected lines could further be used to cross with other null allergenic soybean accessions to breed low allergenic soybean variety.
\end{abstract}

Keywords Soybean, Allergen, Gly m Bd 30K (P34), Molecular marker, Breeding

\section{INTRODUCTION}

Soybean (Glycine max [L.] Merr.) is an important source of vegetable oil and high-protein meal. It is an essential crop in sustainable agriculture for the fixation of nitrogen. However, the increasing use of soybean products in processed foods poses a potential threat to soybeansensitive food-allergic individuals (Herman et al. 2003). Many people suffer from adverse reactions by ingesting and/or inhaling soybean flour and dust (Tsuji et al. 2001). In the USA and in Europe, nearly 5 to $8 \%$ of babies and 2\% of adults are reported to be allergic to soybeans (Heppel et al. 1987); therefore, millions of infants must avoid soybeanbased formula and baby food (Cantani and Lucenti 1997). A total of 38 soybean proteins have been found to be allergens. Among these are Gly m 1a, 1b, Gly m Bd 28k, $30 \mathrm{k}$, Kunitz trypsin inhibitor, 7s globulin, the $a$ and $a$ ' subunits of beta conglycinin and others. These proteins induce allergic reactions using molecular weight of IgEbinding soy protein (Beardslee et al. 2000; Gonzalez et al. 1992; Helm et al. 2000; Metcalfe et al. 1996; Ogawa et al. 2000; Ogawa et al. 1991; Rihs et al. 1999; Rodrigo et al. 1990; Xiang et al. 2008). Symptoms of these allergic reactions usually include fever, vomiting, diarrhea, respiratory problems, gastrointestinal upset and anaphylaxis, which is the most severe allergic reaction and can even cause death (Sampson 2000; Taylor and Kabourek 2003).

In a number of IgE binding studies, it has been shown that more than $65 \%$ of soy-sensitive patients react only with the Gly m Bd 30K (P34) protein (Helm et al.1998;

Received July 30, 2013; Revised September 12, 2013; Accepted September 13, 2013; Published September 30, 2013

*Corresponding author Yul-Ho Kim, kimyuh77@korea.kr, Tel: +82-31-290-6751, Fax: +82-31-290-6742

${ }^{\dagger}$ These authors contributed equally to this work. 
Ogawa et al. 2000; Ogawa et al. 1991, 1993; Yaklich et al. 1999). Even though Gly m Bd $30 \mathrm{~K}$ is a relatively minor seed constituent (less than $1 \%$ of total seed protein), it is regarded as the major or immunodominant soybean allergen. Gly m Bd 30K (P34) can be isolated from the crude $7 \mathrm{~s}$-globulin fraction by gel-filtration chromatography as an oligomeric protein with a molecular weight of more than $3,000,000$ (Ogawa et al. 1993). It is a member of the papain protease superfamily of Cys proteases and exists as a monomeric insoluble glycoprotein consisting of 257 amino acid residues linked together by disulfide bonds that may play a role in its folding. P34 shares 30\% sequence homology with Der $\mathrm{p} 1$, a house dust-mite allergen (Kalinski et al. 1990, 1992; Babiker et al. 2000).

Of the approximately 16,266 soybean accessions from the USDA germplasm collection that were screened, only two were found to have reduced $\mathrm{P} 34$ protein accumulation in seeds (Joseph et al. 2006). The low P34 soybean accessions PI 567476 and PI 603570A were characterized as having normal levels of seed proteins other than P34 (Joseph et al. 2006). An attempt was made to produce a P34-null line using transformation. Herman et al. (2003) used particle bombardment to produce a transgene-induced gene silencing soybean line that did not accumulate the Gly $\mathrm{m} \mathrm{Bd} 30 \mathrm{~K}$ protein in its seeds. The resulting plants and their seeds lacked any compositional, developmental or structural phenotypic differences compared to control plants. Also, proteomic analysis detected the suppression of Gly $\mathrm{m} \mathrm{Bd}$ 30K-related peptides but no other significant changes in the polypeptide pattern. Suppression of P34 protein expression in transgenic soybeans demonstrated that the elimination of the $\mathrm{P} 34$ protein had no negative effect on seed development or final seed composition (Herman et al. 2003).

A comparison between wild-type and mutant sequences revealed that the two low P34 germplasm accessions contain a four base-pair insertion at the P34 start codon (Bilyeu et al. 2009). This mutation may inhibit efficient initiation of translation of the P34 protein, leading to the low P34 phenotype associated with this mutant.

The objective of this research was to develop low allergenic soybean lines using western blot analysis and molecular marker.

\section{MATERIALS AND METHODS}

\section{Plant material and the development of the segregating population}

Low P34 germplasms (PI 567476 and PI 603570A) were obtained from the USDA ARS. The other soybean materials used in this study were Korean elite cultivars which include Daewon, Deapung, Teakwang Sinki and Sowon.

The segregating population was developed from a cross between the conventional P34-containing soybean cultivar (Hwanggum) and the low P34 soybean accession PI567476. $F_{2}$ and $F_{3}$ populations were grown at the National Institute of Crop Science (NICS) at the Rural Development Administration (RDA), Korea in 2009 and 2010. The progenies were developed by the Single Seed Descent Method (SSD) in the greenhouse at the NICS.

\section{Molecular marker and genotyping assays}

Genomic DNA was isolated from $\sim 30 \mathrm{mg}$ leaf tissue using the DNeasy Plant Mini Kit (Qiagen, MD). About 50 ng of genomic DNA were employed for PCR amplification using the primer pair P34low-F(5'-CAAACTGTCATTC CCTGTTGG-3') and P34low-R(5'-AAGAAGCAACAC AAGGAAACC-3') and Ex taq polymerase (Biotools, Spain) according to the manufacturer's recommendations. The PCR mixture was loaded in a PTC-200 thermocycler (MJ Research/Bio-Rad, Hercules, CA, USA) using the following conditions: $95^{\circ} \mathrm{C}$ for $5 \mathrm{~min}$ followed by 35 cycles of $95^{\circ} \mathrm{C}$ for $30 \mathrm{~s}, 60^{\circ} \mathrm{C}$ for $30 \mathrm{~s}$ and $72^{\circ} \mathrm{C}$ for $30 \mathrm{~s}$. PCR products were analyzed by gel electrophoresis $(4 \%$ acrylamide gel) to verify their sizes and to ensure proper amplification. The PCR products were further analyzed for sequencing using the previously described primers.

\section{Southem blot analysis}

Genomic DNA was extracted using the cetyltrimethyl ammonium bromide (CTAB) method and purified by adding $10 \mu \mathrm{g}$ RNase A (Sigma-Aldrich Chemie GmbH). Approximately $20 \mu \mathrm{g}$ of DNA templates of Hwanggeum and PI567476 were digested with various restriction enzymes including EcoR I, BamH I, Sal I, Xba I and Pst I. The digested DNA fragments were fractionated on a $0.8 \%$ agarose gel in $0.5 \times$ TBE buffer. A supercoiled DNA ladder 
(Promega, USA) was used as the size marker. After electrophoresis, Southern blot analysis was conducted with full-length P34 cDNA and a gene-specific probe labeled using DIG-High Prime DNA Labeling, and the resulting signals were detected using a Detection Starter Kit II (Roche Diagnostics, Switzerland).

\section{Antibody and western blots}

The recombinant protein used for antibody production was produced by fusing amino acids 214 through 261 and 351 through 379 of P34-1 to the N-terminus of the glutathione S-transferase tag. About $100 \mathrm{mg}$ cotyledon tissues were ground in liquid nitrogen with $1 \mathrm{ml}$ of protein extraction buffer $(0.1 \mathrm{M}$ Tris/ $150 \mathrm{mM} \mathrm{NaCl} / 0.1 \%$ Tween $20, \mathrm{pH}$ 8.0). Crude cotyledon extracts were resolved on $12.5 \%$ polyacrylamide gels using the Laemmli buffer system. For Western blot analysis, proteins from SDS/ PAGE were electrophoretically transferred to a Hybond P membrane (GE Healthcare, Munich, Germany) using blotting buffer $(25 \mathrm{mM}$ Tris $/ 192 \mathrm{mM}$ glycine $/ 20 \%$ [vol $/ \mathrm{vol}]$ methanol, $\mathrm{pH} 8.3)$. Membranes were blocked with a $6 \%$ $(\mathrm{wt} / \mathrm{vol})$ solution of skim milk powder in TBST $(50 \mathrm{mM}$ Tris/100 mM NaCl/0.05\% Tween 20, pH 7.4) and probed with goat anti-rabbit HRP-conjugated antibodies (StressGen, British Columbia, Canada) diluted in a $6 \%(\mathrm{wt} / \mathrm{vol})$ solution of skim milk powder in TBS $(1: 5,000)$. Bound antibodies were detected using the ECL detection reagent (GE Healthcare).

\section{Stimulation and measurement of degranulation in RBL-2H3 cells}

RBL-2H3 cells were grown as monolayers in minimum essential medium (MEM) with Earle's salts supplemented with glutamine, antibiotics and 15\% FBS. The RBL-2H3 cells were transferred into a 24 -well plate $\left(2 \times 10^{5}\right.$ cells per well). The cells were incubated overnight in complete medium containing $50 \mathrm{ng} / \mathrm{ml}$ DNP-specific IgE. The cultures were washed and buffered medium was added $(0.2 \mathrm{ml} /$ well). Experiments were performed using intact RBL- 2H3 cells in 1,4-piperazinediethanesulfonic acid (PIPES)-buffered medium(25 mM PIPES, pH 7.2, $159 \mathrm{mM} \mathrm{NaCl}, 5 \mathrm{mM} \mathrm{KCl}$, $0.4 \mathrm{mM} \mathrm{MgCl} 2,1 \mathrm{mM} \mathrm{CaCl}_{2}, 5.6 \mathrm{mM}$ glucoseand $0.1 \%$ fatty-acid-free fraction $\mathrm{V}$ from bovine serum). The cells were incubated for $30 \mathrm{~min}$ with or without morin before adding $25 \mathrm{ng} / \mathrm{ml} \mathrm{Ag}$ for $10 \mathrm{~min}$ or for the indicated amount of time. Degranulation was determined by measuring the activity of $\beta$-hexosaminidase, agranule marker, in the culture medium. The release of $p$-nitrophenol from $p-$ nitrophenyl- $N$-acetyl- $\beta$ - D-glucosaminide was measured at $405 \mathrm{~nm}$ using an ELISA kit according to the manufacturer's instructions (Invitrogen-Biosource Cytokinine \& Signaling, Camarillo, CA).

\section{RESULTS}

\section{Three copies of the P34 gene are present in the soybean genome}

To establish the genetic map for P34, genetic mapping was performed using DOE-JGI CSP (fttp://ftp.jgipsf.org /pub/JGI_data/phytozome/v5.0/Gmax/), with simple sequence repeat (SSR) markers placed on the composite map (http://bldg6.arsusda.gov/ pooley/soy/cregan/soymap3.xl s). Using SSR markers, it was found that P34 sequences were located in scaffold 22 between 22.9 and $60.6 \mathrm{cM}$ and in scaffold 3 between 27.8 and $71.4 \mathrm{cM}$. Using in silico mapping based on sequence data, the two scaffolds were placed in two different chromosomes; Scaffold 22 was anchored by Sat_ 212 and Sat 400 on Gm08, while Scaffold 3 contained Satt385 and Sat_171 on Gm05. Glyma08g 12270 and Glyma08g12280 on Scaffold 22 were mapped to Gm08, and Glyma05g29130 on Scaffold 3 was mapped to $\mathrm{Gm} 05$ (Fig.1).

To determine the molecular organization of the P34 genes in the soybean genome, Southern blot analysis was performed (Fig. 2). Genomic soybean DNA was digested with five different restriction enzymes (EcoR I, BamH I, Sca I, Xba I and Pst I) and hybridized with either a full-length cDNA or the promoter region of P34 as the gene-specific probe. When genomic DNA digested with $E c o$ R I, Sca I and $X b a$ I was hybridized with the genespecific probe, three bands were seen. This hybridization pattern, along with the in silico mapping results, suggests that P34 represents a small gene family that is present as three copies in the soybean genome. 

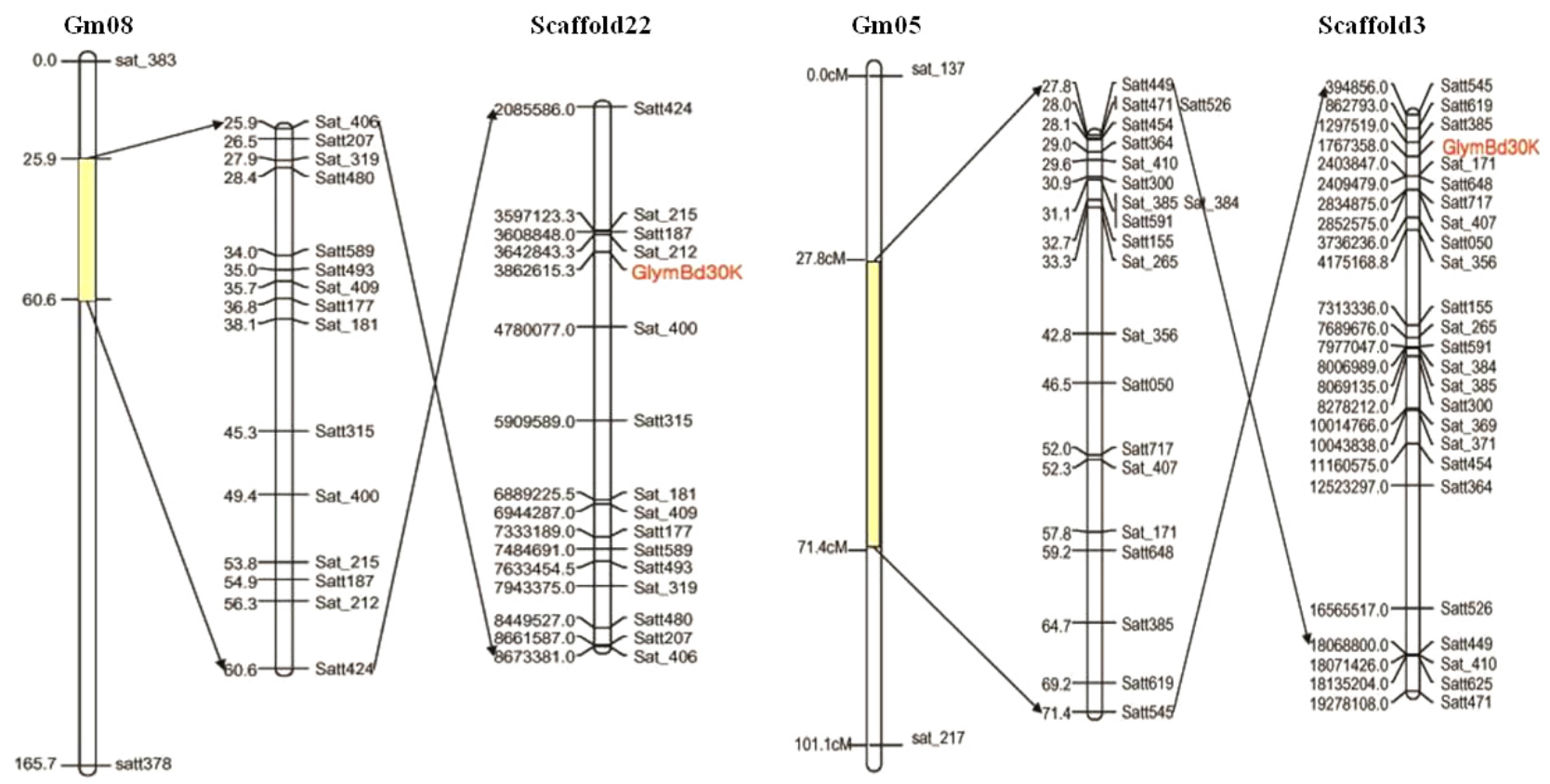

Fig. 1. Scaffold map from the Williams 82 sequence map. The P34 sequence is located in scaffold 22 and scaffold 3, according to the DOE-JGI CSP (fttp://ftp.jgipsf.org/pub/JGI_data/phytozome/v5.0/Gmax/). Scaffold 22 and scaffold 3 are located between 22.9 and $60.6 \mathrm{cM}$ in $\mathrm{Gm} 08$ and between 27.8 and $71.4 \mathrm{cM}$ in Gm05, respectively, as determined using an SSR marker (USDA-ARS soymap3).

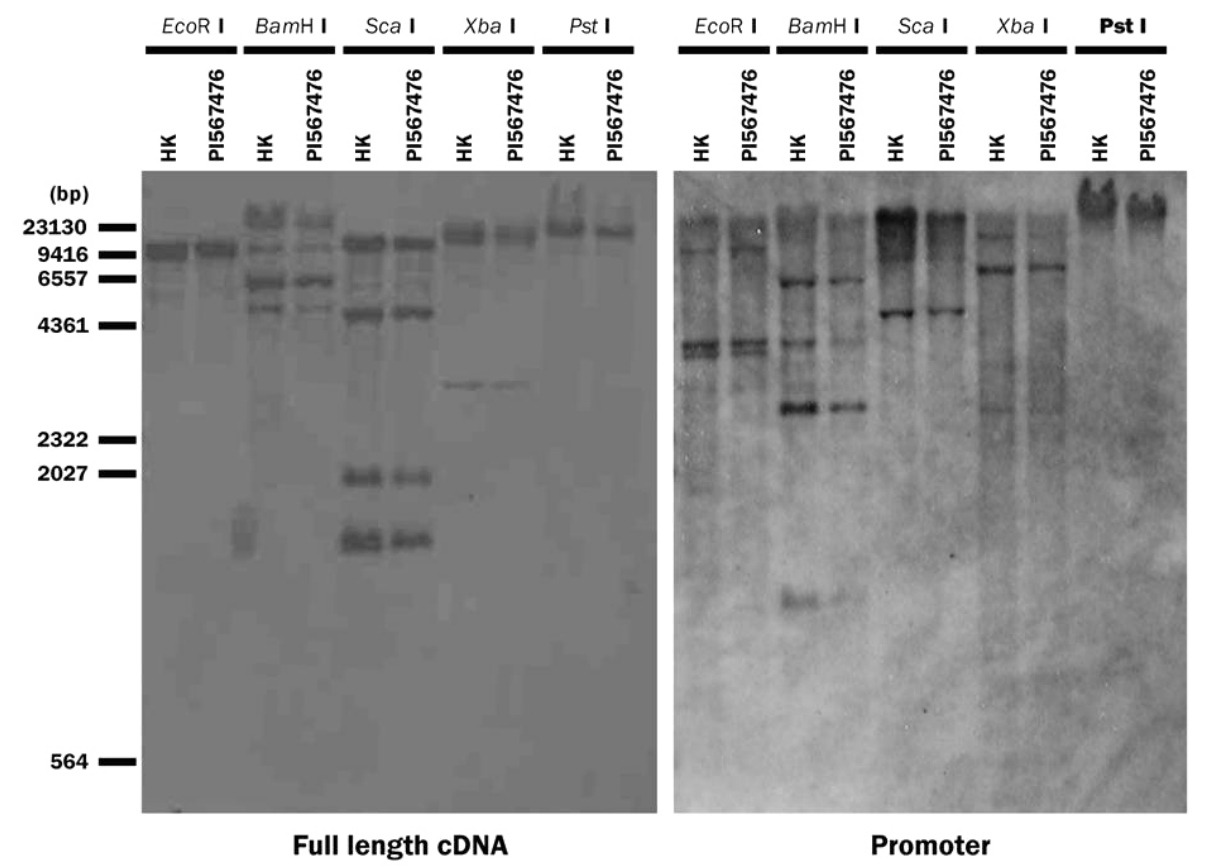

Fig. 2. Genomic Southern blot analysis of P34. Each lane was loaded with $20 \mu \mathrm{g}$ of soybean genomic DNA digested with EcoR I, BamH I, Sal I, Xba I and Pst I, separated on a $0.8 \%$ agarose gel, blotted and probed with DIG-labeled full-length P34 cDNA probe and the gene-specific probe containing the P34 promoter region. The membranes were washed under high stringency conditions $\left(60^{\circ} \mathrm{C}, 20 \mathrm{X} \mathrm{SSC}\right)$. The sizes of the hybridizing signals are indicated, along with the positions of the molecular markers. 
Development of a molecular marker and antibody for selection and breeding of low allergen-containing soybean

To develop a molecular marker for P34, the genomic DNA sequence of AB013289, which was annotated without a cultivar description as "Glycine max gene for $\mathrm{Bd} 30 \mathrm{~K}$ " in
GenBank (www.ncbi.nlm.nil.gov/nuccore), was compared with that of Glyma08g12270, Glyma08g12280 and Glyma 05g29130, and all were found to contain P34. Alleles for AB013289 contain an identical four base-pair insertion at the start codon. Using the newly developed markers, the mutant P34 alleles in PI567476 and PI603579A were
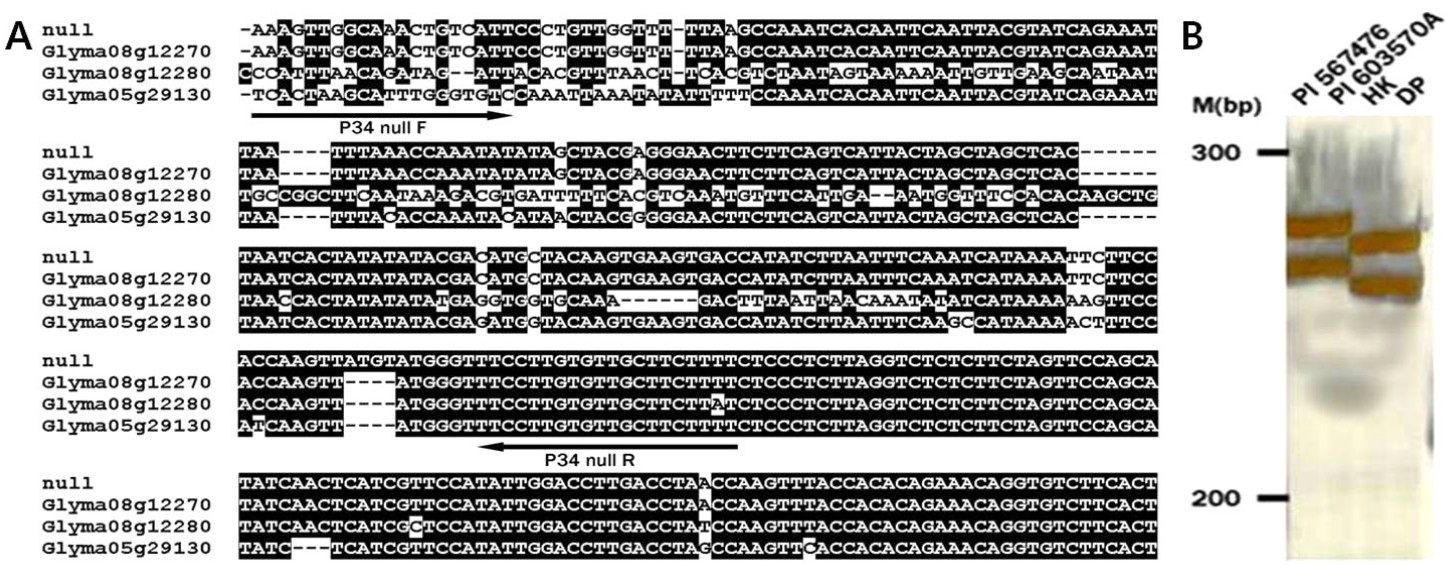

Fig. 3. Nucleotide sequences of P34-related protein and molecular marker assay. (A) Comparison of nucleotide sequences of P34-related proteins. Nucleotide sequences that are conserved in all three proteins are shown in dark gray. The black bar under the sequences represents P34 sequences that were used for the molecular marker assay. Dashes show gaps in the amino acid sequences introduced to optimize alignment. (B) Molecular marker assay in two low P34 germplasms (PI567476 and PI603570A) and two Korean cultivars (DP; Deapung and HW; Hwanggeum). The migration of the size markers is shown to the left of the gel.

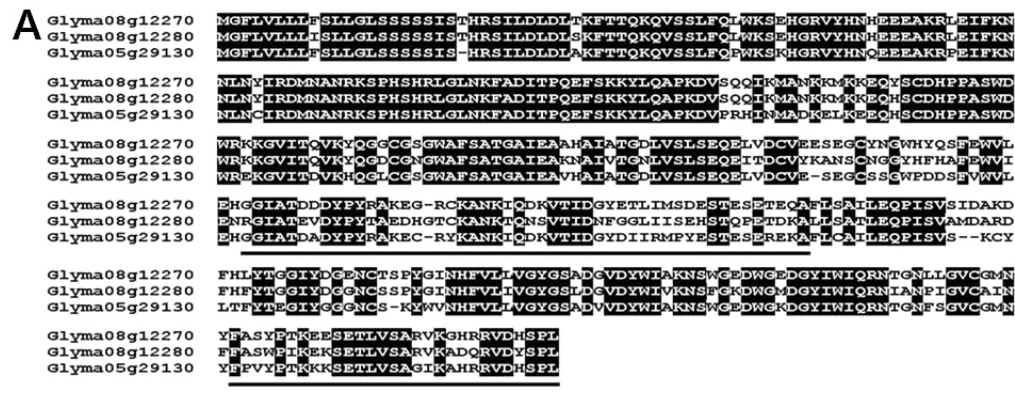

B Soybean P34 Protein epitopes
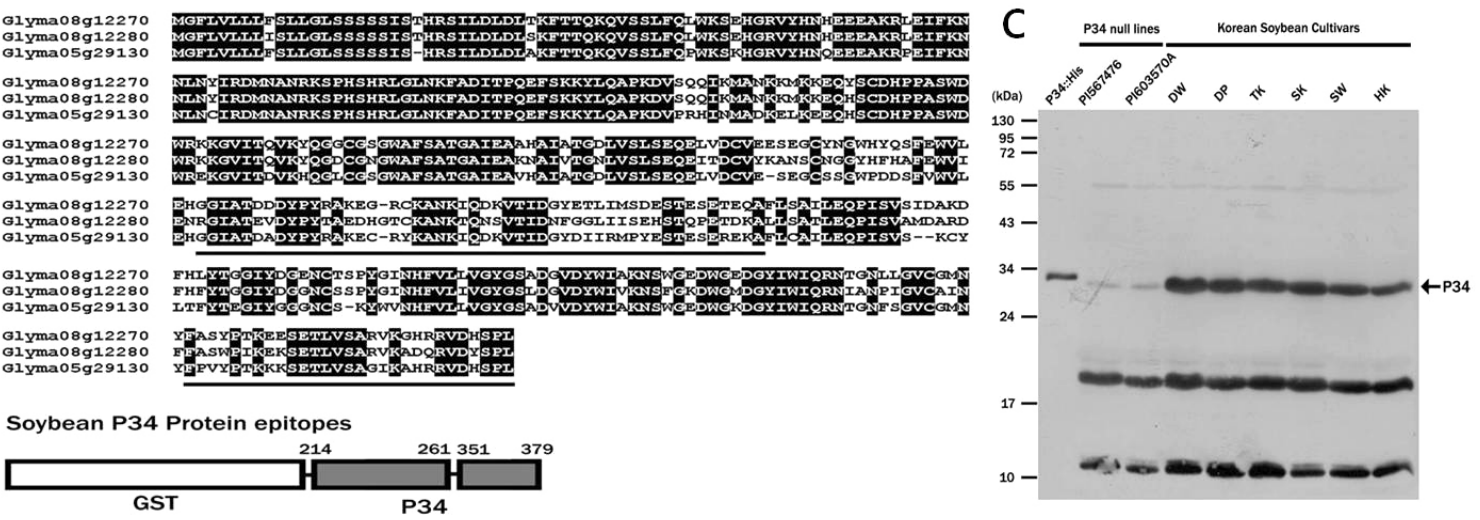

Fig. 4. Deduced amino acid sequences of P34-related proteins and western blot analysis. (A) Comparison of deduced amino acid sequences of P34-related proteins. Amino acid residues that are conserved in all three proteins are shown in dark gray. The black bar under the sequences represents P34 epitopes used for antibody production. Dashes show gaps in the amino acid sequences introduced to optimize alignment. (B) Structure of recombinant protein for antibody production. Amino acids 214 to 261 and 351 to 379 of P34-1 were fused to the N-terminus of the glutathione S-transferase tag. (C) Western blot analysis in two low-P34 germplasms (PI567476 and PI603570A) and six Korean cultivars (DW; Deawon, DP; Deapung, TK; Teakwang, SK; Sinki, SW; Sowon and HW; Hwanggeum). 
validated. Fig. 3B shows the differences in the banding patterns of $\mathrm{P} 34$, on $4 \%$ acrylamide gel, in the mutant lines and the two Korean cultivars (Hwanggum and Daepung). PCR amplification of the molecular marker reliably distinguished plants containing mutant P34 alleles from plants containing wild-type P34 alleles.

To easily select a low-expressing P34 mutant line in the population that resulted from crossing PI567476 with
Hwanggum, recombinant $\mathrm{P} 34$ protein was used to produce a polyclonal antibody (Fig. 4A, B). Western blotting analysis showed that not only purified P34 fusion protein, but also soybean protein extracted from the cotyledons of PI567476, PI603579A and seven Korean cultivars, were detected with the antiserum. P34-His recombinant protein and soybean extracts showed one band of $\sim 30 \mathrm{kDa}$ (Fig. 4C). P34 proteins in PI567476 and PI603579A were less

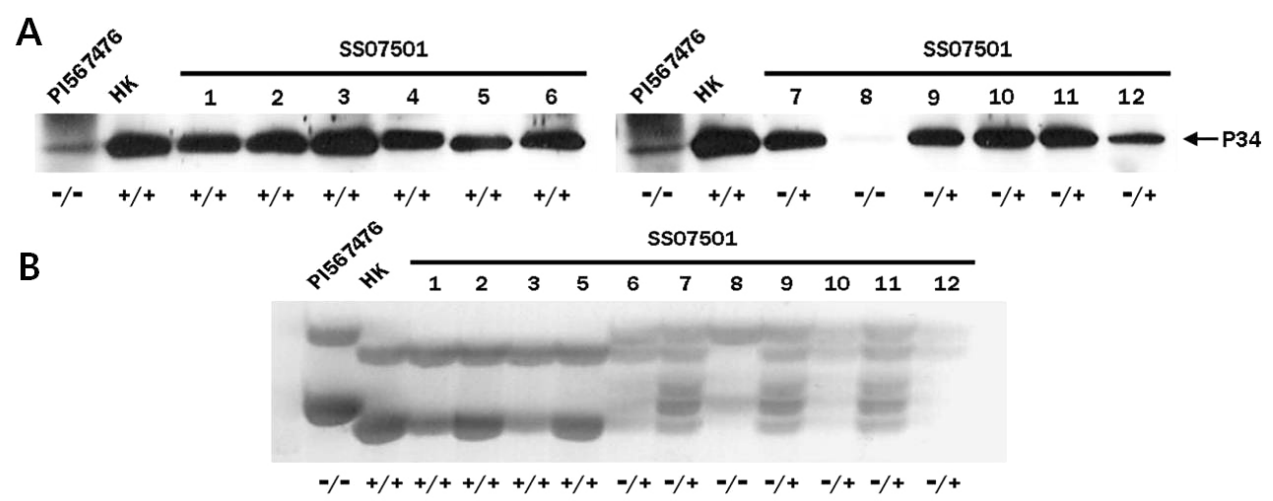

Fig. 5. Western blot analysis and molecular marker assay in the $F_{2}$ population. (A) Western blot analysis in the $F_{2}$ population. (B) Molecular marker assay in the $\mathrm{F}_{2}$ population. PI567476 and Hwanggeum were the parental lines and SS07501 was produced by crossing PI567476 with Hwanggeum. -/-, homozygous lines with a low P34 phenotype; -/+, heterozygous lines; +/+, and homozygous lines with a high P34 phenotype.

A
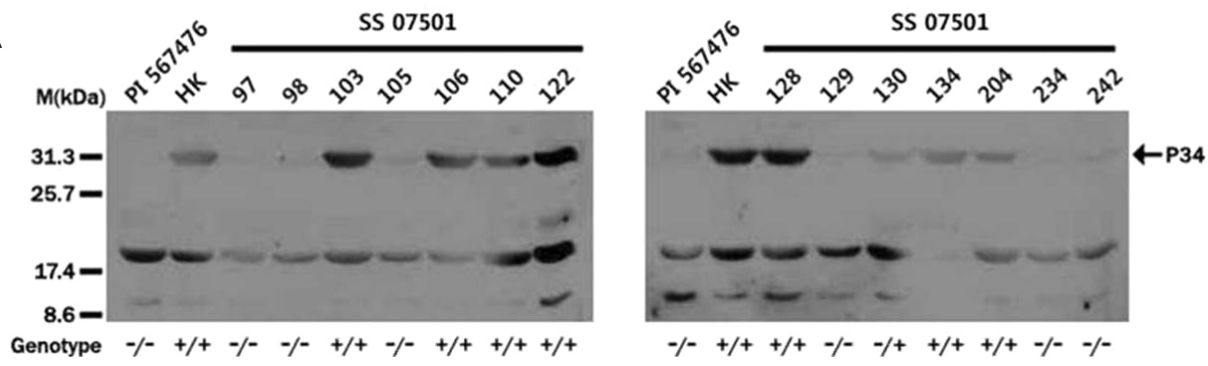

B

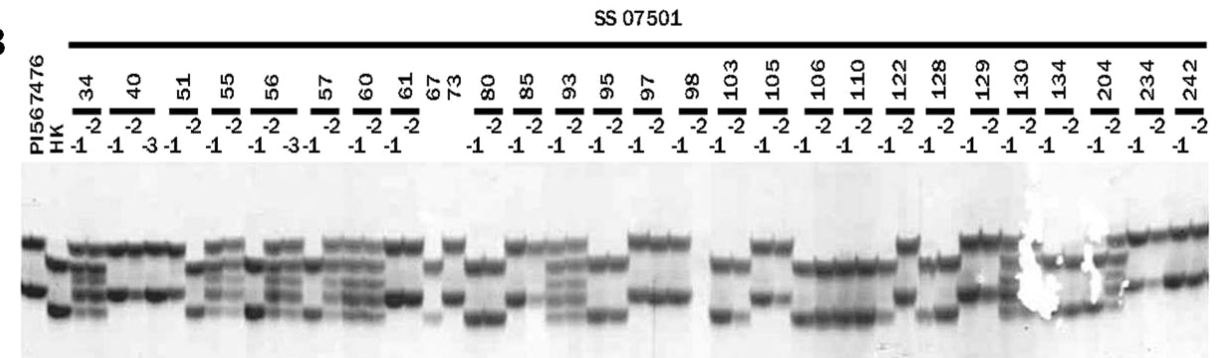

Fig. 6. Western blot analysis and molecular marker assay in the $F_{3}$ population. (A) Western blot analysis of the $F_{2}$ population. (B) Molecular marker assay in the $\mathrm{F}_{3}$ population. PI567476 and Hwanggeum were the parental lines and SS07501 was produced by crossing PI567476 with Hwanggeum. -/-, homozygous lines with a low P34 phenotype; -/+, heterozygous lines; +/+, and homozygous lines with a high P34 phenotype. 
strongly expressed than those in the seven Korean cultivars. In subsequent studies, this molecular marker and polyclonal antibody were used to genotype the progeny produced by crossing PI567476 with Hwanggum.

\section{Linkage analysis of $F_{2}$ and $F_{3}$ genotypes for the low- allergen trait}

To develop a soybean variety with reduced levels of P34 protein, a segregating population was developed from crosses between the Korean soybean cultivar Hwanggum, which contains wild-type levels of P34 protein, and the low-P34 soybean accession PI567476 (Fig. 5A, 6B). The $249 \mathrm{~F}_{2}$ segregating plants derived from the Hwanggum $\times$ PI567476 cross were genotyped using the molecular marker developed in this study. The phenotypes of these plants were determined by probing total proteins extracted from cotyledons with the $\mathrm{P} 34$ polyclonal antibody (Fig. 5B, 6A). The phenotypes were scored as either $-/-,-/+$ or $+/+$, depending on the intensity of across-reacting protein band with the P34 polyclonal antibody. The phenotypes determined from western blot analysis perfectly corresponded to the genotyping results obtained using the molecular marker. For subsequent studies, western blot and marker analyses were performed, and a homozygous -/- line (SS07501-61 and SS07501-105) and a homozygous +/+ line (SS07501-128 and SS07501-134) were selected from the $\mathrm{F}_{3}$ generation.

\section{Effect of total proteins extracted from cotyledons of homozygous parental lines on Ag-stimulated degranulation in rat basophilic leukemia (RBL)-2H3 cells}

Secretion of preformed allergic mediators such as histamine and various proteases in granules is a critical part of the local allergic reaction. Therefore, we determined whether total proteins extracted from cotyledons of parental and homozygous lines inhibited $\mathrm{Ag}$-stimulated degranulation using RBL-2H3 cells. First, the expression levels of P34 proteins in total proteins extracted from cotyledons of parental and homozygous lines were confirmed using the polyclonal antibody isolated in this study. P34 proteins were expressed at low levels in PI567476 and mutant homozygous plants and at high levels in Hwanggum and wild-type homozygous plants. Total proteins extracted from these lines were then found not to inhibit Ag-induced degranulation in RBL-2H3 cells (Fig. 7). Therefore, an anti-allergenic effect was not observed in parental plants PI567476 and Hwanggum.

\section{DISCUSSION}

Genomic Southern blot analysis was carried out to determine the molecular organization of the P34 genes in the soybean genome. Soybean genomic DNA was digested with five different restriction enzymes (EcoR I, BamH I, Sal I, Xba I and Pst I) and hybridized with either a full-length cDNA as the full-length probe or the promoter region of P34 as the gene-specific probe. When the genespecific probe was used, three fragments were visualized. This result confirmed that the $\mathrm{P} 34$ gene is present in more than three copies in the soybean genome. These hybridization patterns concur with the in silico mapping results. The P34 gene and one of the pseudogenes are in $\mathrm{Gm} 08$, and another

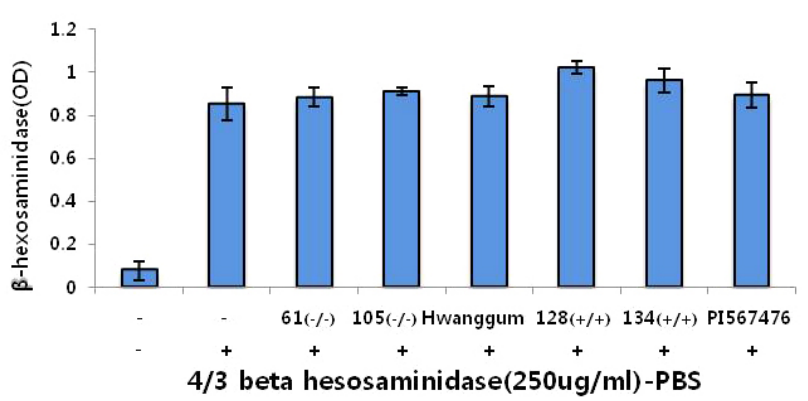

Fig. 7. The anti-allergic effects of total proteins extracted from the cotyledons of parental and homozygous lines. The anti-allergic effect was assessed using a PCA mouse model. The values indicate mean \pm S.E.M. from three independent experiments. 
pseudogene identical to GenBank accession AB013290 appeared to reside on Gm05 (Bilyeu et al. 2009). We developed a co-dominant marker that recognizes a different location than previous report based on the sequence of Glyma08g12270 containing a four base-pair insertion at the P34 start codon (Fig. 3A). PCR amplification using the molecular marker reliably distinguished plants containing mutant P34 alleles from plants containing wild-type P34 alleles (Fig. 3B).

A polyclonal antibody was designed using information derived from a comparative analysis of the amino acid sequences of Glyma08g12270, Glyma08g12290 and Glyma 05g29130 and used for western blot analysis (Fig. 4A). The recombinant P34 protein was expressed in Escherichia coli, purified and used to produce the polyclonal antibody (Fig. 4B). This antibody was employed to easily select a low-expressing P34 mutant line from the population generated by crossing PI567476 with Hwanggum. Western blot analysis of the expression of the $\mathrm{P} 34$ protein using this antibody revealed that two low-expressing P34 mutant lines (PI567476 and PI603570A) and six Korean cultivars (Deawon, Deapung, Teakwang, Sinki, Sowon and Hwanggeum) showed different patterns of expression. The P34 protein was clearly expressed in the six Korean cultivars, forming a band of about $30 \mathrm{kDa}$, but the expected P34 band was indistinct in the mutant germplasms. P34 proteins in PI567476 and PI603579A alleles were less expressed than those in seven Korean cultivars. This result contradicts the study of Joseph et al. (2006), who found that PI567476 and PI603579A were null for P34 protein.

It has been shown that more than $65 \%$ of soy-sensitive patients react only to the Gly m Bd 30K protein (Ogawa et al. 1991). Secretion of preformed allergic mediators such as histamine and various proteases in granules is a critical part of the local allergic reaction. Total protein extracted from the cotyledons of parental and homozygous lines were tested to determine whether these proteins inhibited Ag-stimulated degranulation using RBL-2H3 cells. These proteins failed to inhibit Ag-induced degranulation in RBL-2H3 cells and were therefore allergenic. Our results suggest that PI567476 is as allergenic as Hwanggum because it contains allergenic proteins other than P34. But at cellular level, the homozygous lines did not appear to be non-allergenic. These results suggest that gene pyramiding of other null-allergic proteins (28K, Gly m 1a, 1b, kunitz trypsin inhibitor and others) is equally important.

\section{ACKNOWLEDGMENT}

This work was supported by grants from the R\&D project (PJ008741022013) of the National Institute of Crop Science, Rural Development Administration, Republic of Korea.

\section{REFERENCES}

Babiker EE, Azakami H, Ogawa T, Kato A. 2000. Immunological characterization of recombinant soy protein produced by Escherichia coli Expression System. J Agric Food Chem. 48: 571-575.

Beardslee TA, Zeece MG, Sarath G, Markwell JP. 2000. Soybean gycinin G1 acidic chain shares IgE epitopes with peanut allergen Ara $h$ 3. Int Arch Allergy Immunol. 123: 299-307.

Bilyeu K, Ren C, Nguyen HT, Herman E, Sleper DA. 2009. Association of a four-basepair insertion in the P34 gene with the low-allergen trait in soybean. The Plant Genome. 2(2): 141-149.

Cantani A, Lucenti P. 1997. Natural history of soy allergy and/or intolerance in children, and clinical use of soyprotein formulas. Pediatr Allergy Immunol. 8(2): 59-74.

Choi MS, Kim YH, Park HM, Seo BY, Jung JK, Kim ST, Kim MC, Shin DB, Yun HT, Choi IS, Kim CK, Lee JY. 2009. Expression of BrD1, a plant defensin from Brassica rapa, confers resistance against brown planthopper (Nilaparvata lugens) in transgenic rices. Mol Cells. 28(2): 131-137.

Gonzalez R, Polo F, Zapatero L, Caravaca F, Carreira J. 1992. Purification and characterization of major inhalant allergens from soybean hulls. Clin Exp Allergy. 22: 748-755.

Helm RM, Cockrell G, Herman E, Burks AW, Sampson HA, Bannon GA. 1998. Cellular and molecular characterization of a major soybean allergen. Int Arch Allergy Immunol. 117: 29-37.

Helm RM, Cockrell G, Connaughton C. 2000. Mutational analysis of the IgE-binding epitopes of P34/Gly m Bd 30K. J Allergy Clin Immunol. 105: 378-384. 
Heppel LM, Sissons JW, Pedersen HE. 1987. A comparison of the antigenicity of soya-bean-based infant formulas. Br J Nutr. 58: 393-403.

Herman EM, Helm RM, Jung R, Kinney AJ. 2003. Genetically modification removes and immunodominant allergen form soybean. Plant Physiology. 132: 36-43.

Joseph LM, Hymowitz T, Schmidt MA, Herman EM. 2006. Evaluation of Glycine germplasm for nulls of the immunodominant allergen P34/Gly m Bd 30K. Crop Sci. 46: 1755-1763.

Kalinski A, Weisemann JM, Matthews BF, Herman EM. 1990. Molecular cloning of a protein associated with soybean seed oil bodies that is similar to thiol Proteases of the papain superfamily. J Biol Chem. 265: 13843-13848.

Kalinski A, Melroy DL, Dwivedi RS, Herman EM. 1992. A soybean vacuolar protein (P34) Related to thiol proteases is synthesized as a glycoprotein precursor during Seed Maturation. J Biol Chem. 267: 12068-12076.

Metcalfe DD, Astwood JD, Townsend R, Sampson HA, Taylor SL, Fuchs RL. 1996. Assessment of the allergenic potential of foods derived from genetically engineered crop plants. Crit Rev Food Sci Nutr. 36(suppl): S165S186.

Ogawa A, Samoto M, Takahashi K. 2000. Soybean allergens and hypoallergenic soybean products. J Nutr Sci Vitaminol (Tokyo). 46: 271-279.

Ogawa T, Bando N, Tsuji H, Okajima H, Nishikawa K, Sasaoda K. 1991. Investigation of the IgE-binding proteins in soybeans by immunoblotting with the sera of soybean- sensitive patients with atopic dermatitis. J Nutr Sci Vitaminol (Tokyo). 34: 555-565.

Ogawa T, Tsuji H, Bando N. 1993. Identification of the soybean allergenic protein, Gly $\mathrm{m} \mathrm{Bd} 30 \mathrm{~K}$, with the soybean $34-\mathrm{kDa}$ oil-body-associated protein. Biosci Biotechnol Biochem. 57: 1030-1033.

Rihs HP, Chen Z, Rueff F. 1999. IgE binding of the recombinant allergen soybean profilin (rGly m 3 ) is mediated by conformational epitopes. J Allergy Clin Immunol. 104: 1293-1301.

Rodrigo MJ, Morell F, Helm RM. 1990. Identification and partial characterization of the soybean-dust allergen involved in the Barcelona asthma epidermic. J Allergy Clin Immunol. 85: 778-784.

Sampson HA. 2000. Food anaphylaxis. Br Med Bull. 56: 925-935.

Taylor SL, Kabourek JL. 2003. Soyfoods and allergies: Separating fact from fiction. The Soy Connection. 11: 1-6.

Tsuji H, Hiemori M, Kimoto M, Yamashita H, Kobatake R, Adachi M, Fukuda T, Bando N, Okita M, Utsumi S. 2001. Cloning of cDNA encoding a soybean allergen, Gly $\mathrm{m} \mathrm{Bd}$ 28K. Biochimica et Biophysica Acta. 1518: 178-182.

Xiang P, Baird LM, Jung R, Zeece MG, Markwell J, Sarath G. 2008. P39, a novel soybean protein allergen, belongs to a plant-specific protein family and is present in protein storage vacuoles. J Agric. Food Chem. 56: 2266-2272.

Yaklich RW, Helm RM, Cockrell G, Herman EM. 1999. Analysis of the distribution of the major soybean seed allergens in a core collection of Glycine max accessions. Crop Sci. 39: 1444-1477. 